\title{
The impact of educational and environmental interventions in Dutch worksite cafeterias
}

Ingrid Steenhuis

Patricia van Assema

Gerard van Breukelen

Karen Glanz

Gerjo Kok

Hein de Vries

Published as:

Steenhuis, I.H.M., Assema, P. van Breukelen, G. van, Glanz, K. Kok, G. \& Vries, H. de. (2004). The impact of educational and environmental interventions in Dutch worksite cafeterias. Health Promotion International, 19 (3), 335-343. 


\section{The impact of educational and environmental}

interventions in Dutch worksite cafeterias

word count

abstract: 274

text: 4080 


\begin{abstract}
Environmental interventions as labeling of healthy foods and an increased availability of healthy foods may help consumers to meet the guidelines for a healthy diet. This article describes a study into the effectiveness of two environmental programs to be used in worksite cafeterias along with an educational program. The aim of the interventions was to reduce fat intake and increase fruit and vegetable intake. In the 'Labeling Program', low fat products were labeled. The 'Food Supply Program' comprised an increased availability of low-fat products and fruits and vegetables in worksite cafeterias. The 'Educational Program' consisted of information about healthy nutrition through brochures, table tents, a self help manual and posters. The design consisted of a pretest-posttest experimental control group design, with four conditions: the Educational Program, the Food Supply Program plus Educational Program, the Labeling Program plus Educational Program and a control group. Seventeen worksites were randomly assigned to one of the four research conditions. Total fat, fruit, and vegetable intake was measured with a quantitative, selfadministered food frequency questionnaire (35 questions). Intake during lunch was measured by asking respondents to write down which food items they had purchased during their last lunch in the cafeteria. Furthermore, sales data for some targeted product categories were collected (milk, butter, cheese, meat products, desserts). For the whole study population, no significant effects on consumption data were found for any of the programs. The data showed a beneficial significant treatment effect of the Labeling Program on total fat intake, for respondents who believe they eat a high fat diet. Sales data revealed a significant effect of the labeling program on desserts, but not for the other products.
\end{abstract}

Keywords: nutrition education, worksite, labeling 


\section{Introduction}

Dietary factors have been found to be important in the prevention of cancer and coronary heart diseases (Joshipura et al., 1999; van Leer et al., 1999; Liu et al., 2000, Willet, 2001). However, mean fat intake in the Netherlands is still too high, as in many other countries. Fruit and vegetable consumption on the other side, is still too low (Netherlands Bureau for Food and Nutrition, 1998). Therefore, effective methods for achieving large scale dietary changes are needed. Environmental strategies may help consumers to meet the guidelines for a healthy diet and can be defined as strategies that reduce barriers or increase opportunities for healthful choices (Glanz \& Mullis, 1988).

Being a point-of-choice setting, worksite cafeterias are especially suitable for environmental interventions (Glanz \& Mullis, 1988). Different environmental strategies have been used in worksites. A few studies reported on changes in food offerings. Jeffery et al. (1994) used, succesfully, a reduction of $50 \%$ in the price of fruit and salads in combination with an increase of fruit and salad bar choices. Wilbur et al. (1981) found positive effects for increasing low-calorie offerings in vending machines. Various studies analyzed the impact of labeling of healthy food items in worksite cafeterias (see Dubbert et al., 1984; Holdsworth \& Haslam, 1998; Levin, 1996; Mayer et al., 1987; Schmitz \& Fielding, 1986; Sorenson et al., 1992). Most of the reported labeling programs were implemented in combination with an educational program including, for example, posters or brochures, (Sorenson et al., 1992). In most studies using labeling, effects on the purchases of labeled items were found (Dubbert et al., 1984; Levin, 1996; Schmitz \& Fielding, 1986; Sorenson et al., 1992). The effects varied in magnitude, duration and consistency. Mayer et al. (1987) did not find increases in the purchases of labeled items.

While environmental interventions to change dietary behaviors in worksites are promising strategies, it is still unclear exactly how effective they are. Many studies using environmental interventions were combined with educational elements (Mayer et al., 1987; Sorenson et al., 1992) or with other 
environmental interventions (e.g. Jeffery et al., 1994). Hence, it is impossible to determine the unique contribution of separate environmental interventions. The objective of this study was to assess the separate effects of two environmental interventions (i.e. changes in food supply and labeling) aiming at reducing fat intake and increasing fruit and vegetable consumption in worksite cafeterias. An educational program with an environmental component (the increase of healthy food supply or the labeling) was compared to a program with only educational elements, as well as with no intervention at all.

\section{Methods}

\section{Study design and procedures}

The study used a randomized pretest-posttest experimental design. Seventeen worksite cafeterias of large Dutch companies and governmental organizations with mainly white collar workers were recruited through the head offices of catering organizations. Approximately 35 companies were approached to participate, approximately half of them refused for example because of time reasons. The main inclusion criteria were a minimum of 400 cafeteria visitors a day and a range of food items that allowed an increase of at least four further food items, as well as labeling. Cafeterias were randomly assigned to one of four experimental conditions:

1. Food Supply Program plus Educational Program

2. Labeling Program plus Educational Program

3. Educational Program

4. No Program, control

\section{Measures}

Two different data collection methods were used for this impact evaluation. A cohort of regular visitors of the cafeteria was asked to fill out a quantitative, self-administered questionnaire one month before, one 
month after and six months after the start of the intervention. Respondents were recruited during lunch time in the cafeteria. In total, 5,425 questionnaires were handed out (varying from 255-350 per cafeteria). In the questionnaires, fat-, fruit-, and vegetable intake were measured with a short food frequency list, validated in earlier research (van Assema et al., 1992; van Assema et al., 2001). In this list, fat consumption was expressed in 'fat-points'. One fat point is about four grams of fat. The list consists of 35 questions covering 19 (categories of) food items, including milk and milk products, bread, cheese, meat and meat products, gravy and sauces, snacks, and cookies. Also in the questionnaires, food choice during lunch in the cafeteria was measured by asking respondents to write down what they ate the last time they had a meal in the cafeteria. Socio-demographic variables were measured, as well as possible influencing factors such as BMI (body mass index), household size, cooking behavior, shopping behavior, following a diet or being a vegetarian. Furthermore, respondents were asked to indicate on a seven point scale in their view they were eating a high fat diet or not. In the posttest questionnaire one month after the start of the intervention, respondents were also asked about their opinions and reactions toward the nutrition program in their cafeteria. This was measured on seven point scales. Data of the third questionnaire were only used to compute total fat, fruit and vegetable intake.

Sales data of some targeted product categories (milk, butter, cheese, meat products, desserts) were collected for each company. Mean sales data per week were collected the three weeks before and during the first month of the intervention period.

\section{Statistics}

Total fat, fruit, and vegetable consumption scores were computed. Fat, fruit, and vegetable intake during lunch was also computed. Because the data were clustered, a random-effects regression model was initially used for the analysis. The software packages MIXREG and MIXOR were used to perform the multi-level analysis (Hedeker \& Gibbons, 1996). 
The same regression model was used for all outcomes, as well as for the attrition analysis. The independent variables used in the model were the baseline recording of the outcome at hand, study arm, educational level, BMI and shopping behavior. For assessing intervention effects, dummy variables were used with control (NP) and education only (EP) as reference category, depending on the relevant comparison (i.e. of an environmental program with EP or NP).

For most outcomes (including fat, fruit and vegetables intake in general and during lunch) the multi-level analysis ran into numerical estimation problems, probably due to a near-zero intraclass correlation and/or small sample size (i.e. only 17 worksites). In that case, covariates were removed from the model until an estimate of the intraclass correlation could be obtained. This estimate was nearly always $<0.001$, indicating absence of a random cluster effect. If the intraclass correlation is zero, an ordinary regression analysis with persons as unit of analysis and ignoring their nesting within worksites is correct. However, it is also known that an estimated intraclass correlation of 0 can also be due to a small sample size at the highest level, i.c. a small number of worksites. If the intraclass correlation is not zero, even if it is very small, this ordinary analysis is invalid and will underestimate the standard errors of the intervention effects. In that case, an aggregated analysis with worksites as unit of analysis (using the average of all persons within that worksite as observation) is a valid method to evaluate our intervention effects, albeit less powerful than multilevel analysis due to varying sample sizes per worksite and the fact that only very few covariates can be included into this analysis (Moerbeek, 2000). Since in this study the estimates of the intraclass correlation were nearly always $<0.001$, indicating absence of a random cluster effect, we chose to run the full model with covariates with individuals as unit of analysis, using the SPSS program (SPSS INC., 1999). However, to check the validity of our conclusions, for the main outcomes (fat, fruit and vegetable intake at baseline and first posttest) as well as for significant results found with the individuals as unit of analysis, an aggregated analysis (using worksites as level of analysis) was also run. For the other outcomes (reach of the intervention and respondent's reactions) multi-level analyses were performed. 
The intraclass correlation varied from 0.001 to 0.028 , except for the variable 'number of people that ordered the self help manual' which had an intraclass correlation of .20, indicating a very strong worksite effect on this variable. To test for differences in baseline characteristics of research groups such as age or educational level, and respondents' reactions to the programs, an alpha of .05 was used. Also for the main outcomes, fat-, fruit- and vegetable intake, an alpha of .05 was used. In the tables, both p-values of $<.01$ and $<.05$ are reported.

Sales data were analyzed with SPSS, with worksite as the unit of analysis ( $\mathrm{n}=17)$. The three preintervention scores were combined to one mean pre-intervention score. First, a repeated measurements procedure was run with treatment as a between-subject factor, the pre-intervention score as covariate, and the post-intervention weeks (1-4) as repeated measures. No linear trend was found in the sales data, and therefore final analyses were conducted using the mean sales data for the intervention period. ANCOVA was used to analyze differences between the environmental programs and other programs, with a correction for pre-intervention sales data. Comparisons were made within product groups, and not across product groups. An alpha of .05 was used for these analyses.

\section{Intervention}

Two environmental programs and one educational program were developed to be used in worksite cafeterias. The intervention was mainly designed for white collar workers. The duration of the programs was one month, and they could be prolonged and supported up to six months, which all included worksite cafeterias did. All three programs were based on the outcomes of a preliminary study analyzing conditions for program development and implementation (Steenhuis et al., 2001). The intervention programs were pretested among catering managers and consumers and adapted based on the results of this pretest. 


\section{Educational Program (EP)}

In the EP, determinants of eating less fat and more fruit and vegetables were targeted. In the beginning of the program information was given to increase awareness and to change attitudes, while later on the program focused more on increasing self-efficacy, teaching skills and to manage social influences. The EP consisted of several elements, some of which were basic and therefore obligatory, and others were optional for the worksite cafeterias. The basic elements were posters, brochures, table tents and a self help manual. People could obtain the self help manual for free by filling out a coupon that was included in the brochures. Optional elements were information in the worksite newsletter, badges for worksite cafeteria personnel and a contest. In the beginning of the program more information was given to increase awareness and to change attitudes, while later on the program focused more on increasing self-efficacy and teaching skills.

\section{Food Supply Program (FSP)}

The FSP comprised an increased availability of low-fat products, as well as an increased availability of fruits and vegetables. Six product categories were included: butter/margarine, milk, cheese, meat products, desserts and snacks. Attention was drawn to the new added products by putting a sign in front of them with the phrase "new and healthy" on it, and with posters and table tents.

\section{Labeling Program (LP)}

In the LP, low-fat products in the six food product categories (see above) were labeled with a sign in front of the product. Information on the label consisted of the program logo, the name of the item and the indication that the product was low-fat (see Figure 1). Fruits and vegetables were also labeled. The labeling was explained to the cafeteria visitors on posters and table tents.

-Figure1- 


\section{Results}

\section{Response and respondents}

Total response at baseline (t1) was $30.1 \%$, and varied from $28.1 \%$ to $32.9 \%$ in the various conditions. Of the questionnaires, received at baseline, 151 were excluded from the study, because they were not filled out or had more than $50 \%$ missing items. Response at t 2 was $76.4 \%$, and varied from $57.9 \%$ to $82.1 \%$ in the various conditions. At t2, 53 questionnaires were excluded, again because they were not completely filled out. In total, complete data (t1 and t2) from 1,013 respondents were used in the analysis. Of these 1,013 respondents, $61.3 \%$ also completed the third questionnaire $(n=621)$. Data of these respondents were used for the analysis of the effects on total fat, fruit and vegetable consumption after six months. Attritionpercentages at $\mathrm{t} 2$ did not differ significantly between the conditions. The attrition analysis showed that gender, age, level of education and fat, fruit and vegetable consumption were not significantly associated with attrition.

Mean age of the respondents was 38 years (range 18-64). The majority of respondents were male (62\% male, 38\% female), and had a high level of education (60\% high, 38\% middle, $2 \%$ low). Mean BMI of the study population was 23.6. Twenty-seven percent had a BMI of 25 or higher, of which three percent had a BMI of 30 or higher. A small proportion of the study population reported underweight $(\mathrm{BMI}<20)$. A large majority of the respondents lived together with others (81\%), cooked regularly (64\%) and did the shopping for their household regularly (79\%). Only a few respondents were, according to themselves, following a diet $(8 \%)$ or were vegetarian (6\%).

Respondents in the FSP had a significant lower level of education compared to respondents in the EP (FSP 44\% high level of education vs $71 \%$ in the EP). Also, respondents in the FSP had a significantly higher BMI than respondents in the EP (24.0 vs 23.3) and a larger proportion of the respondents in the FSP did the shopping for their household regularly compared to respondents in the NP condition (84\% vs 72\%). 
The other socio-demographic variables did not differ significantly at baseline between both environmental intervention groups and the EP or NP. Further, no significant differences at baseline were found between the conditions for consumption levels of fat, fruit and vegetables.

\section{Reach of the intervention and respondents' reactions}

Almost all respondents had seen at least something of the nutrition programs in the cafeteria. Nearly half of the respondents in the LP reported having seen the labels. A quarter of the respondents in the FSP reported that they had noticed new, healthy products in the assortment of their cafeteria. On average, the worksites in the FSP added seven low-fat products or servings of fruit and vegetables to their offerings. In the LP and EP, 7\% ordered the self help manual, while in the FSP almost a third of the respondents ordered the manual. However, this was due to a worksite effect and was not an effect of study arm (pvalue FSP vs EP .68 using multilevel analysis; icc .20). Respondents in all three programs had a positive general opinion about the programs (mean FSP, EP 1.1, LP 1.0, range $-3+3$ ). The personal relevance of the programs was rated lower (mean FSP, EP -0.1, LP -0.3, range -3 +3).

\section{Total fat, fruit, and vegetable intake}

Mean total fat scores and fruit and vegetable consumption at baseline and one month after the start of the intervention are shown in Table 1. Mean fat and fruit consumption stayed more or less the same in the environmental programs, while vegetable consumption decreased among all groups. Regression analysis with persons as unit of analysis revealed no significant differences with respect to posttest, correcting for baseline consumption and other covariates (educational level, BMI and shopping behavior), between environmental interventions and the EP and NP respectively (all p-values $\geq .12$ ). These analyses were repeated with consumption scores six months after start of the intervention as dependent variable $(n=621)$. Mean fat intake at $\mathrm{t} 3$ varied from 16.7 fat points (FSP) to 17.7 (LP), mean fruit intake varied from 1.8 
pieces per day (FSP) to 2.1 pieces per day (LP), and mean vegetable intake from 143 grams per day (FSP) to 166 grams per day (LP). No significant differences were found between environmental interventions and the EP and NP respectively (all p-values $\geq .16$ ).

Total fat scores and fruit and vegetable consumption at baseline and posttest (t2) per condition, using worksites as unit of analysis, were very similar to the individual scores presented in Table 1. Regression analysis with worksites as unit of analysis revealed no significant differences between research groups with respect to posttest scores, correcting for baseline scores (all p-values $\geq .08$ ).

\section{-Table 1-}

It is possible that many respondents did not experience a need to change their fat, fruit and vegetable consumption, since many of them thought that their consumption levels were not very high (fat) or low (fruit and vegetables) to begin with. Of all respondents, 19\% $(n=194)$ indicated at baseline that their own fat consumption was (very) high ('aware' people). For fruit intake, 39.8\% $(\mathrm{n}=403)$ indicated at baseline that their intake was (very) low, for vegetable intake 18.8\% $(n=190)$. It could be that the interventions especially were effective for this specific group of 'aware' respondents. To test this hypothesis, we tested the presence of interaction between baseline awareness (yes/no) and treatment condition (LP, FSP, EP, $\mathrm{NP}$ ) on posttest consumption, using pretest consumption as covariate (two-way ANOVA with covariate). For fat consumption, the omnibus test using all four treatment conditions showed no interaction ( $\mathrm{p}=.18$ ). Pairwise comparisons between FSP and EP; FSP and NP; and EP and NP failed to show interaction as well (p-values .75, .41 and .49 respectively). However, a pairwise comparison between LP and EP showed a trend toward interaction ( $\mathrm{p}=.09$ ), while a pairwise comparison between LP and NP showed a significant interaction effect $(p=.04)$. For fruit intake, as well as for vegetable intake, no interaction between baseline awareness (yes/no) and treatment condition (LP, FSP, EP, NP) could be demonstrated (all p-values fruit 
intake $\geq .60$, all p-values vegetable intake $\geq .63$ ). Based on these results, the initial analysis of treatment effect on posttest fat consumption, corrected for pretest fat consumption, educational level, BMI and shopping behavior was repeated within each of the two subgroups, unaware and aware respondents. For unaware respondents, no significant treatment effects were found (p-values $\geq .13$ ). In the aware group, a significant beneficial treatment effect was found for the LP compared to the NP $(\mathrm{p}<.05)$ (number of fat points in the LP decreased from 19.9 at t1 to 18.4 at t2, compared to 19.0 at t1 and 19.7 at t2 for the NP), but not for the other comparisons ( $\mathrm{LP}$ vs EP $\mathrm{p}=.08$, all other $\mathrm{p}$-values $\geq .54$ ). The analyses for the aware group were repeated with worksites as unit of analysis, with consumption at baseline included as the only covariate in the model. A significant beneficial treatment effect was found for the LP compared to both the $\mathrm{NP}(\mathrm{p}<.01)$ and the EP $(\mathrm{p}<.05)$. The same procedure to test for interaction of treatment with (subjective) awareness was also carried out with respect to fat consumption levels six months after the start of the intervention ( $\mathrm{n}=62)$. No significant interaction was found.

\section{Fat, fruit, and vegetable intake during lunch in the worksite cafeteria}

Table 2 shows the quantity of fat, fruit, and vegetable consumption during lunch in the cafeteria. No significant differences were found between groups with respect to fat, fruit and vegetable consumption at t2, corrected for consumption at $\mathrm{t} 1$ and the covariates included in the model (educational level, BMI, shopping behavior) (all p-values $\geq .12, .35, .09$ respectively for fat, fruit and vegetable intake). For fat, fruit and vegetable intake during lunch in the cafeteria, interaction analyses between (subjective) awareness of own consumption levels and study arm on behavior change were performed using the same method as outlined for total fat, fruit and vegetable intake. No significant interactions were found (all p-values $\geq .13$, $.75, .08$ respectively for fat, fruit and vegetable intake).

\section{- Table 2-}




\section{Sales data}

Table 3 shows sales proportions of low-fat products per product group. Comparisons of the environmental programs with the EP and NP on post-intervention sales data, corrected for pre-intervention sales data, revealed a significantly better effect of the LP compared to the EP and NP regarding desserts (LP vs EP, $\mathrm{p}<.01$; LP vs NP, $\mathrm{p}<.05$ ). For the other products, no significant differences were found.

-Table 3-

\section{Discussion}

The aim of this study was to assess the effectiveness of two environmental interventions. No significant effects were found between the environmental programs and the educational or control condition on total fat, fruit, and vegetable intake one month or six months after the start of the intervention. Also, no significant effects were found on intake during lunch in the worksite cafeteria. The decrease in all research groups on vegetable intake was possibly caused by seasonal effects (baseline measure in September, posttest in December). No convincing evidence of treatment by awareness interaction was found for fruit and vegetable intake. Regarding total fat intake, the data showed a treatment effect of the LP for respondents who believe they eat a high fat diet. However, this interaction of treatment by awareness was no longer present at $\mathrm{t} 3$. For intake during lunch at the cafeteria at $\mathrm{t} 2$, no interaction effects were demonstrated at all.

Sales data confirm, for the most part, the results of the survey of food consumption. A main effect of the LP was found only for desserts. For some other products a trend in the positive direction could be observed, for example for cheese. Because of the limited number of worksite cafeterias included in this study, it is difficult to detect possible significant effects on sales data. 
Although around $90 \%$ of the respondents claimed to have seen something of the intervention programs, considerable fewer respondents reported seeing the labeling or the new, healthy products. Labels might have been too inconspicious to get enough attention. Because the available food choices in worksite cafeterias were changing continuously, it is not too surprising that only $26 \%$ of the respondents in the FSP noticed new, healthy products. This does not necessarily mean that no behavioral change can be achieved. However, it might have had a minimal influence.

Another possible explanation for the ineffectiveness of the interventions, might have been the length of the programs. The initial intervention period was one month, and the programs could be supported up to six months. It is recommended that interventions should remain for a longer period of time in order to be succesfull in changing dietary behavior (Contento et al., 1995). However, worksite cafeterias are not always willing to implement an intervention program for such a long period of time and prefer programs that are designed as a short 'action-period' (a few weeks) (Steenhuis et al., 2001).

The majority of the research population were men. It is possible that men are more resistant to nutrition education, which might have accounted for the lack of effects in this study. In relation to this, healthiness was the main focus of the interventions. It could be, that the intervention would have been more succesfull, especially for men, if the main focus of the intervention was not on healthiness, but on tastiness for example.

Jeffery et al. (1994) found an effect of increasing the number of fruit and salad offerings. They also decreased the price of fruit and salads. It might be that a simultaneous price reduction is necessary to achieve an effect of the environmental interventions. Although not all labeling studies have shown effects (e.g. Mayer et al., 1987), most studies have (Dubbert et al., 1984; Levin, 1996; Schmitz \& Fielding, 1986; Sorenson et al., 1992). Schmitz \& Fielding (1986) found an effect of labeling on total intake of calories, but not on fat intake during lunch in the cafeteria. So, it may be that visitors in worksite cafeterias are 
more interested in and susceptible to changes in the caloric-content of products rather than in the fat content of products, as we focused on in our study. However, guidelines for healthy nutrition in the Netherlands do not focus on a certain (maximum) number of calories per day, but rather recommend to reduce the intake of (saturated) fat.

Previously reported evaluation studies of environmental interventions suffered from methodological weaknesses: not all studies used a control condition and most studies only measured program effects on consumption in the cafeteria. In this way, the influence of the environmental program on total diet is not clear: will people also eat more low-fat alternatives at home? Does the labeled food item replace another item eaten at the cafeteria or at home or is it added to usual intake? Our study tried to take into account these omissions. This may have accounted for the apparent lack of impact in this trial. In future research regarding intervention programs using environmental elements, attention should be drawn to the visibility and attractiveness of the labels and possible combinations with price-reduction strategies. Furthermore, the labeling might focus not only on fat content, but also on caloric value. 


\section{References}

Assema, P. van, Brug, J., Kok, G., Brants, H. (1992). The reliability and validity of a Dutch questionnaire on fat consumption as a means to rank subjects according to individual fat intake. European Journal of Cancer Prevention, 1, 375-380.

Assema, P. van, Brug, J., Ronda, G., Steenhuis, I. (2001). The relative validity of a short Dutch questionnaire as a means to rank adults and adolescents to total and saturated fat intake. Journal of Human Nutrition and Dietetics, 14, 377-390.

Contento, I., Balch, G.I., Bronner, I.L., Paige, D.M., Gross, S.M., Bisignani, L., Lytle, L.A., Maloney, S.K., White, S.L., Olson, C.M., Sharaga Swadener, S., Randell, J.S. (1995). The effectiveness of nutrition education and implications for nutrition education policy, programs, and research: a review of research. Journal of Nutrition Education, 27.

Dubbert, P.M., Johnson, W.G., Schlundt, D.G., Montague, N.W. (1984). The influence of caloric information on cafeteria food choices. Journal of Applied Behavioral Analysis, 17, 85-92.

Glanz, K., Mullis, R.M. (1988). Environmental interventions to promote healthy eating: A review of models, programs and evidence. Health Educuation Quarterly, 15, 395-315.

Hedeker, D., Gibbons, R.D. (1996). MIXREG: a computer program for mixed-effects regression analysis with autocorrelated errors. Computer Methods and Programs in Biomedicine, 49, 229-252.

Holdsworth, M., Haslam, C. (1998). A review of point-of-choice nutrition labelling schemes in the workplace, public eating places and universities. Journal of Human Nutrition and Dietetics, 11, 423445.

Jeffery, R.W., French, S.A., Raether, C., Baxter, J.E. (1994). An environmental intervention to increase fruit and salad purchases in a cafeteria. Preventive Medicine, 23, 788-792.

Joshipura, K.J., Ascherio, M.D., Manson, J.E., Stampfer, M.J., Rimm, E.B., Speizer, F.E., Hennekes, C.H., Spiegelman, D., Willett, W.C. (1999). Fruit and vegetable intake in relation to risk of ischemic stroke. Journal of the American Medical Association, 282, 1233-1239. 
Leer, E.M. van, Cleton, F.J., Leeuwen, F.E. van (eds). (1999). Signaleringsrapport kanker 1999 (Indicative cancer report). Amsterdam, Nederlandse Kankerbestrijding.

Levin, S. (1996). Pilot study of a cafeteria program relying primarily on symbols to promote healthy choices. Journal Nutrition Education, 28, 282-285.

Liu, S., Manson, J.E., Lee, I.M., Cole, S.R., Hennekes, C.H., Willett, W.C., Buring, J.E. (2000). Fruit and vegetable intake and risk of cardiovascular disease: the Women's Health Study. American Journal of Clinical Nutrition, 72, 922-928.

Mayer, J.A., Brown, T.P., Heins, J.M., Bishop, D.B. (1987). A multi-component intervention for modifying food selections in a worksite cafeteria. Journal of Nutrition Education, 19, 277-280. Mayer, J.A., Dubbert, P.M., Elder, J.P. (1989). Promoting nutrition at the point of choice: A review. Health Education Quarterly, 16, 31-43.

Netherlands Bureau for Food and Nutrition (Voedingscentrum) (1998) Zo eet Nederland, resultaten van de voedselconsumptiepeiling 1997-1998 (This is how the Netherlands eats: results of the food consumption survey 1997-1998). Voedingscentrum, 's Gravenhage 1998.

Schmitz, M.F., Fielding, J.E. (1986). Point-of-choice nutritional labeling: Evaluation in a worksite cafeteria. Journal of Nutrition Education, 18, s65-s68.

SPSS Inc. (1999). Statistical Package for the Social Sciences, version 9.01. SPSS: Chicago, IL. Sorenson, G., Morris, D.M., Hunt, M.K., Hebert, J.R., Harris, D.R., Stoddard, A., Ockene, J.K. (1992). Work-site nutrition intervention and employees' dietary habits: The Treatwell program. American Journal of Public Health, 6, 214-224.

Steenhuis, I.H.M., Assema, P. van, Glanz, K. (2001). Strengthening environmental and educational nutrition programmes in worksite cafeterias and supermarkets in the Netherlands. Health Promotion International, 1, 21-31.

Wilbur, S.R., Zifferblat, S.M., Pinsky, J.L., Zifferblat, S. (1981). Healthy vending: A cooperative pilot 
research program to stimulate good health in the marketplace. Preventive Medicine, 10, 85-93.

Willett, W.C. (2001). Diet and cancer: One view at the start of the millenium. Cancer Epidemiology, Biomarkers and Prevention, 10, 3-8. 
Table 1 Mean total fat, fruit, and vegetable intake at baseline (t1) and posttest (t2) (mean(sd))

\begin{tabular}{llllll}
\hline Total $\mathrm{n}=1013$ & & $\begin{array}{l}\mathrm{LP} \\
(\mathrm{n}=215)\end{array}$ & $\begin{array}{l}\text { FSP } \\
(\mathrm{n}=290)\end{array}$ & $\begin{array}{l}\text { EP } \\
(\mathrm{n}=293)\end{array}$ & $\begin{array}{l}\mathrm{NP} \\
(\mathrm{n}=215)\end{array}$ \\
\hline $\begin{array}{l}\text { Fat } \\
\text { (fat points per day) }\end{array}$ & $\mathrm{t} 1$ & $17.7(6.3)$ & $17.1(5.7)$ & $17.5(6.2)$ & $17.7(6.1)$ \\
& & $17.3(6.2)$ & $16.8(5.7)$ & $17.6(6.0)$ & $17.7(6.2)$ \\
& & & & \\
Fruit & $\mathrm{t} 1$ & $2.1(1.7)$ & $2.0(1.6)$ & $2.0(1.5)$ & $2.1(1.8)$ \\
$\quad$ (servings per day) & $\mathrm{t} 2$ & $2.2(1.6)$ & $2.1(1.6)$ & $2.1(1.6)$ & $2.0(1.6)$ \\
& & & & & \\
$\begin{array}{l}\text { Vegetables } \\
\quad \text { grams per day) }\end{array}$ & $\mathrm{t} 1$ & $170.1(92.6)$ & $155.3(89.5)$ & $168.0(86.7)$ & $144.6(82.6)$ \\
& $\mathrm{t} 2$ & $156.4(87.0)$ & $148.3(80.4)$ & $157.6(85.9)$ & $142.9(83.5)$ \\
\hline
\end{tabular}

$(\mathrm{LP}=$ Labeling program; FSP= Food supply program; $\mathrm{EP}=$ Educational program; $\mathrm{NP}=$ No program $)$ no significant differences 
Table 2 Mean fat, fruit, and vegetable intake during lunch in the cafeteria at baseline (t1) and posttest (t2) (mean(sd))

\begin{tabular}{|c|c|c|c|c|c|}
\hline Total $n=941$ & & $\begin{array}{l}\mathrm{LP} \\
(\mathrm{n}=202)\end{array}$ & $\begin{array}{l}\text { FSP } \\
(\mathrm{n}=265)\end{array}$ & $\begin{array}{l}\mathrm{EP} \\
(\mathrm{n}=275)\end{array}$ & $\begin{array}{l}\mathrm{NP} \\
(\mathrm{n}=199)\end{array}$ \\
\hline \multirow{2}{*}{$\begin{array}{l}\text { Fat } \\
\text { (grams per lunch) }\end{array}$} & $\mathrm{t} 1$ & $21.9(13.1)$ & $20.4(14.9)$ & $20.3(15.6)$ & $20.6(12.0)$ \\
\hline & $\mathrm{t} 2$ & $21.5(15.2)$ & 19.7 (12.4) & $20.9(13.4)$ & $21.6(12.3)$ \\
\hline \multirow{2}{*}{$\begin{array}{l}\text { Fruit } \\
\text { (grams per lunch) }\end{array}$} & $\mathrm{t} 1$ & 79.8 (99.1) & $58.2(93.0)$ & 71.8 (102.9) & 78.5 (91.6) \\
\hline & $\mathrm{t} 2$ & 87.9 (106.5) & $76.6(101.4)$ & 84.5 (103.5) & 80.7 (116.1) \\
\hline \multirow{2}{*}{$\begin{array}{l}\text { Vegetables } \\
\text { (grams per lunch) }\end{array}$} & $\mathrm{t} 1$ & $20.1(44.8)$ & $19.6(33.2)$ & $20.0(28.2)$ & $17.2(27.8)$ \\
\hline & $\mathrm{t} 2$ & $14.9(23.7)$ & 20.8 (31.9) & $19.6(28.7)$ & $18.1(25.6)$ \\
\hline
\end{tabular}

(LP= Labeling program; FSP= Food supply program; EP= Educational program; $\mathrm{NP}=$ No program) no significant differences 
Table 3 Sales proportions (\%) of low-fat products per product group (mean (sd))

\begin{tabular}{|c|c|c|c|c|c|c|c|}
\hline & & $\begin{array}{l}\text { Milk } \\
(n=16)\end{array}$ & $\begin{array}{l}\text { Butter } \\
(n=12)\end{array}$ & $\begin{array}{l}\text { Cheese } \\
(n=12)\end{array}$ & $\begin{array}{l}\text { Meat prod. } \\
(n=15)\end{array}$ & $\begin{array}{l}\text { Desserts } \\
(n=16)\end{array}$ & \\
\hline \multirow{6}{*}{ LP } & $\begin{array}{l}\text { pre- } \\
\text { intervention }\end{array}$ & $94.8(3.2)$ & $61.5(5.5)$ & $8.9(3.2)$ & 54.8 (18.5) & $28.6(12.6)$ & \\
\hline & week 1 & $95.0(3.9)$ & $50.8(15.9)$ & $10.0(3.7)$ & 52.7 (21.9) & 42.1 (18.3) & \\
\hline & week 2 & $96.1(3.5)$ & $55.0(12.0)$ & $25.2(24.1)$ & $55.1(23.1)$ & $45.8(9.5)$ & \\
\hline & week 3 & $94.9(4.0)$ & $55.0(12.6)$ & $17.5(3.1)$ & $51.0(24.7)$ & $45.0(10.7)$ & \\
\hline & week 4 & $95.3(4.2)$ & 56.1 (13.9) & $22.6(12.8)$ & $51.8(24.7)$ & 44.9 (6.7) & \\
\hline & intervention & $95.3(3.8)$ & $54.2(13.5)$ & $18.8(6.0)$ & 52.7 (22.9) & $44.4(10.2)$ & $\begin{array}{l}\mathrm{LP}>\mathrm{EP}^{* *} \\
\mathrm{LP}>\mathrm{NP}^{*}\end{array}$ \\
\hline \multirow{6}{*}{ FSP } & $\begin{array}{l}\text { pre- } \\
\text { intervention }\end{array}$ & $92.5(6.6)$ & $58.4(25.4)$ & $26.2(26.7)$ & $38.6(19.0)$ & $37.2(14.1)$ & \\
\hline & week 1 & $92.2(5.9)$ & $54.1(29.3)$ & 30.6 (26.9) & $43.6(14.5)$ & $42.8(15.2)$ & \\
\hline & week 2 & $91.6(6.6)$ & $58.3(27.7)$ & 28.6 (27.3) & 45.9 (17.5) & 35.0 (12.8) & \\
\hline & week 3 & $92.1(6.1)$ & $58.9(26.1)$ & 31.9 (25.9) & $52.0(15.8)$ & 39.6 (13.9) & \\
\hline & week 4 & $92.2(6.4)$ & $61.8(21.4)$ & 32.0 (24.3) & 47.0 (18.7) & $46.6(23.5)$ & \\
\hline & intervention & $92.0(6.2)$ & $58.3(26.1)$ & 30.8 (25.9) & 47.1 (16.5) & $41.0(8.7)$ & \\
\hline \multirow{6}{*}{ EP } & $\begin{array}{l}\text { pre- } \\
\text { intervention }\end{array}$ & $93.7(5.2)$ & $53.8(2.4)$ & $16.7(7.2)$ & $40.4(4.2)$ & $21.0(4.8)$ & \\
\hline & week 1 & $91.7(7.2)$ & $57.4(2.5)$ & $14.1(5.8)$ & $44.5(10.2)$ & $23.2(5.4)$ & \\
\hline & week 2 & $92.0(7.0)$ & $65.1(23.4)$ & $16.2(5.6)$ & $51.1(8.9)$ & $23.8(7.5)$ & \\
\hline & week 3 & $92.8(6.5)$ & $71.2(21.1)$ & $16.7(6.5)$ & 46.2 (13.9) & 24.7 (6.9) & \\
\hline & week 4 & 91.9 (6.9) & $70.8(20.6)$ & $18.2(5.4)$ & $61.7(21.2)$ & $26.9(12.5)$ & \\
\hline & intervention & $92.1(6.9)$ & $66.1(15.4)$ & $16.3(5.8)$ & $50.9(11.4)$ & $24.7(7.1)$ & \\
\hline \multirow{6}{*}{ NP } & $\begin{array}{l}\text { pre- } \\
\text { intervention }\end{array}$ & $94.2(7.7)$ & 70.4 (29.7) & $42.3(45.5)$ & 66.1 (34.9) & $44.2(40.5)$ & \\
\hline & week 1 & $94.6(6.5)$ & $68.5(30.7)$ & $34.6(48.5)$ & $69.5(36.6)$ & $43.5(34.5)$ & \\
\hline & week 2 & $94.8(6.1)$ & $69.0(29.8)$ & $34.4(49.0)$ & $67.8(34.2)$ & 45.3 (34.5) & \\
\hline & week 3 & $94.6(6.5)$ & $71.1(26.9)$ & $34.4(50.3)$ & $72.7(29.4)$ & 46.1 (33.9) & \\
\hline & week 4 & $90.3(14.3)$ & 65.7 (26.9) & $34.7(50.1)$ & $67.7(26.8)$ & $46.8(32.2)$ & \\
\hline & intervention & $93.6(8.2)$ & $69.9(28.6)$ & 34.5 (49.5) & $69.4(31.6)$ & $45.4(33.4)$ & \\
\hline $\begin{array}{l}* \mathrm{p} \\
\text { Prop } \\
\text { Pre-i } \\
\text { Inter }\end{array}$ & $\begin{array}{l}5 ;{ }^{* *} \mathrm{p}<.01 \\
\text { ion of low-fat pr } \\
\text { rvention= pre-in } \\
\text { ttion= interventi }\end{array}$ & $\begin{array}{l}\text { lucts on total s } \\
\text { rvention perio } \\
\text { period (mean }\end{array}$ & $\begin{array}{l}\text { s in product gr } \\
\text { nean of three } \\
\text { week } 1 \text { throug }\end{array}$ & $\begin{array}{l}\mathrm{p} \\
\text { asures) } \\
\text { ) }\end{array}$ & $\begin{array}{l}\mathrm{LP}=\text { Labelin } \\
\mathrm{FSP}=\text { Food } \mathrm{s} \\
\mathrm{EP}=\text { Educati } \\
\mathrm{NP}=\text { No prog }\end{array}$ & $\begin{array}{l}\text { ogram } \\
\text { ly program } \\
\text { l program } \\
\text { n }\end{array}$ & \\
\hline
\end{tabular}




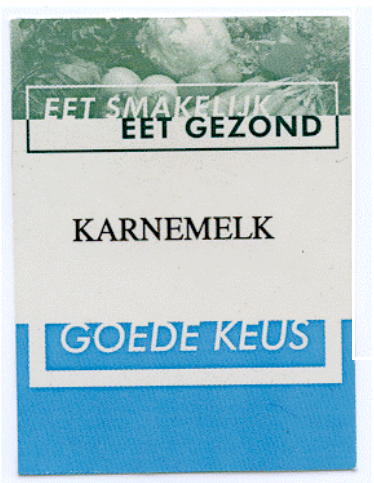

Figure 1 Example of labeling (text: Eat tasty and healthy. Buttermilk, a good choice) 